\title{
A Study of Ocular Changes Occurring in Blood Dyscrasias
}

\author{
Sudhanshu Abhay Banka', Kaberee Bhuyan Medhi \\ ${ }^{2}$ Associate professor, Department of Pathology, FAAMCH, Barpeta, Assam
}

\begin{abstract}
Introduction: The ocular manifestations of blood dyscrasias are protean and reflect to the high vascularity and unique vascular anatomy of the eye. They may be present along with disordered findings of the cellular elements of blood or may arise during the course of the disease or as a consequence of treatment. Objective: The study is undertaken to describe the various ocular changes seen in blood disorders and also to know the relationship between the degree of these changes and the coexisting blood picture. Methodology: This is a study of 135 patients of various age groups with different types of hematological disorders for a period of one year from July2007 to June 2008 at Regional Institute of Ophthalmology, Gauhati Medical College Hospital, Guwahati, Assam. Results and Observations: Out of 135 patients, 76 patients(57\%) had hematological malignancies, Acute Myeloid Leukemia being the single largest group; 49 patients(36\%) with anemia and 10 patients(7\%) had bleeding disorders. $60 \%$ out of 135 patients examined for ocular findings showed retinopathy in 47 patients(34.81\%). Discussion: The ocular changes of blood dyscrasias are not uncommon as is proved by various clinical and pathological studies. These changes in the eye are due to the hemorrhagic effect of the blood disorders or due to the infiltration of the ocular tissues by malignant cells.
\end{abstract}

Keywords: dyscrasias, hematological, retinopathy, malignancy, ocular

\section{Introduction}

The word dyscrasia comes from the Greek language and means "bad temperament" . In the older medical literature, the term was used to indicate disease. Currently the phrase blood dyscrasia was used to indicate a pathological condition of the cellular elements of the blood. An increase or decrease in the total number of red cells in a given patient is referred as polycythaemia or anemia respectively. A large population of atypical or neoplastic white blood cells within the blood constitutes leukemia. A subnormal number of platelets in the circulating blood ( thrombocytopenia) or loss of normal platelet function can lead to bleeding disorders or coagulopathies.

The ocular manifestations of blood dyscrasias are varied. Both the high vascularity and unique vascular anatomy of the eye play a role in the ocular manifestations of hematological diseases. The blood dyscrasias may present with ocular involvement, or ocular manifestations may arise during their course or ocular findings may arise as a consequence of treatment.

Independent of the pathogenic mechanism, anemia may cause nerve fiber layer hemorrhage and infarcts, white centre retinal hemorrhages and occasional vitreous hemorrhage. The severity of the hemorrhages is related to both the degree of anemia and presence of thrombocytopenia.

Ocular involvement in leukemia has long been recognized and virtually every ocular tissue may be affected. Involvement of orbit, lids, conjunctiva, sclera, uvea, retina and optic nerve are well documented. Cornea being avascular, is relatively spared and involvement of lens is unknown. The incidence of ocular involvement at sometime during the course of leukemia ranges as high as $90 \%{ }^{1}$
Ocular involvement may be because of direct invasion by leukemic cells or changes may be brought indirectly through various hemodynamic alterations. Guyer and associates ${ }^{2}$ evaluated the relationship between leukemic retinopathy lesions and hematological parameters at the time of diagnosis. They found an association between the intraretinal hemorrhages and thrombocytopenia as well as low hematocrit while white cotton wool spots were not associated with hematological parameters.

Ocular manifestations of thrombocytopenia included papilloedema, extraocular muscle palsies and visual field defects, which usually result in concomitant CNS findings. Retinal findings consist of hemorrhages, vascular occlusions and serous detachments.

The significance of ocular changes in different blood dyscrasias, relationship between hematological alterations and the effect of treatment on these are not however properly understood.

\section{Materials and Methods}

A total of 135 patients of various age groups with different types of blood dyscrasias were studied between July 2007 and June 2008 at Regional Institute of Ophthalmology, Gauhati Medical College Hospital. The patients were diagnosed and treated by the departments of Hematology and Pediatrics of the same hospital. The study included freshly diagnosed cases to those receiving treatment and both indoor and outdoor patients. The findings of detailed history, blood and systemic examination findings and treatment history were recorded in the Proforma prepared for the study.

Ophthalmic examination and investigations included visual acuity for near and distant vision, Intraocular pressure measurement with a Schiotz tonometer, complete slit lamp bio microscopy of the anterior segment of the eyeball, 


\section{International Journal of Science and Research (IJSR) \\ ISSN (Online): 2319-7064 \\ Index Copernicus Value (2013): 6.14 | Impact Factor (2015): 6.391}

gonioscopy using a two mirror indirect gonio lens and evaluation of the fundus was done using the direct as well as indirect ophthalmoscopy and findings were recorded on the proforma. Imaging of the central nervous system, fundus angiography, B-scan of the eyes in cases indicated were noted down too.

Statistical analysis of the findings was done and unpaired student's t test results was used to compare the various hematological parameters with the incidence of retinopathy.

\section{Results and Observations}

270 eyes of 135 patients with different blood dyscrasias were examined in the study.

Age and Sex Distribution: Amongst the135 patients examined, 49(36.29\%) were females and 86(63.71\%) were males. 35(25.92\%) out of 135 patients belonged to the pediatric age group $(<18$ yrs) while 100 patients $(74.08 \%)$ belonged to the adult age group. The youngest patient was 7 months of age whereas the oldest was 81 years of age.

Table1: Age and sex distribution of the patients

\begin{tabular}{|c|c|c|c|}
\hline & Males & Females & Total \\
\hline$<18$ yrs & 22 & 13 & 35 \\
\hline 18 yrs and above & 64 & 36 & 100 \\
\hline Total & 86 & 49 & 135 \\
\hline
\end{tabular}

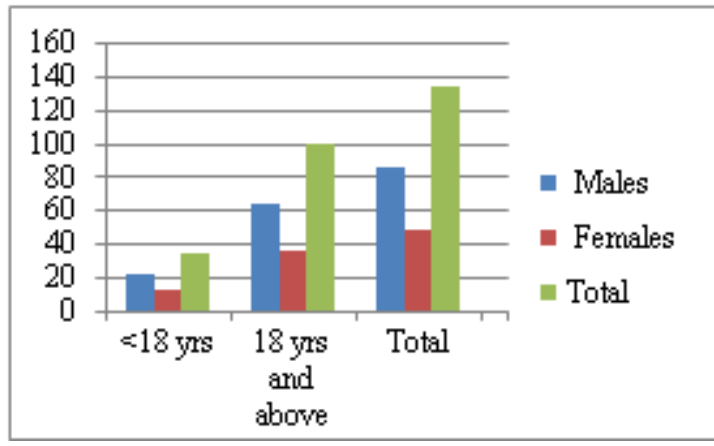

Chart 1: Age and sex distribution of the patients

Incidence of Different Blood Dyscrasias: In this series of 135 patients, patients with various blood dyscrasias after examination could be broadly classified belonging to -

1) Hematological malignancies: 76 patients (57\%)

2) Anemia: 49 patients (36\%)

3) Bleeding disorders: 10 patients (7\%)

Out of the total of 76 patients with hematological malignancies, maximum number suffered from acute leukemias (44 patients, 57.89\%), with Acute Myeloid Leukemia being the single largest group , 26 patients.18 patients suffered from Acute Lymphoblastic Leukemia. Chronic leukemia (Chronic Myeloid Leukemia-7, Chronic Lymphocytic Leukemia - 3) and Multiple Myeloma accounted for 10 patients each. Lymphomas were diagnosed in 11 patients, while Myelodysplastic Syndrome was diagnosed in 1 patient.

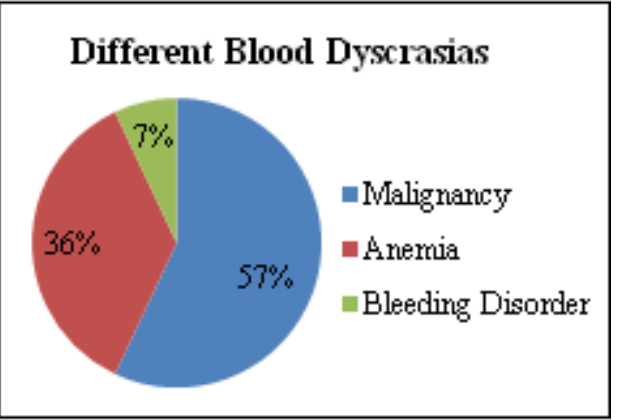

Chart 2: Distribution of patients across various disease groups

Table 2: Incidence of various hematological malignancies

\begin{tabular}{|c|c|}
\hline Disease & No of patients \\
\hline AML & 26 \\
\hline ALL & 18 \\
\hline CML & 7 \\
\hline CLL & 3 \\
\hline MM & 10 \\
\hline MDS & 1 \\
\hline NHL & 8 \\
\hline HD & 3 \\
\hline
\end{tabular}

AML-Acute Myeloid leukemia, ALL -Acute Lymphoblastic Leukemia, CML- Chronic Myeloid Leukemia, CLLChronic Lymphocytic Leukemia, MM- Multiple Myeloma, MDS- Myelodysplastic Syndrome, NHL- Non Hodgkin Lymphoma, HD- Hodgkin Lymphoma

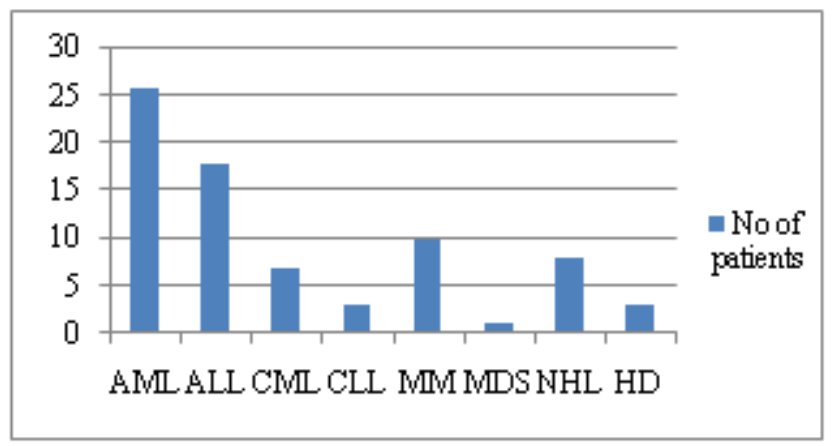

Chart 3: Incidence of various haematological malignancies

Incidence of various types of anaemia : Amongst the 49 patients belonging to the group of anemia, 19 patients(38.78\%) were diagnosed with iron deficiency anemia. 10 patients suffered from different thalassemias, whereas $9(18.36 \%)$ patients were diagnosed with aplastic anemia. Megaloblastic anemia accounted for 4 patients while the diagnosis for 5 patients was hemolytic anemia and another 2 patients 2 patients suffered from anemia of chronic disease.

Table 3: Incidence of various types of anemia

\begin{tabular}{|c|c|}
\hline Disease & No of patients \\
\hline IDA & 19 \\
\hline Thal & 10 \\
\hline AA & 9 \\
\hline HA & 5 \\
\hline MGA & 4 \\
\hline AOCD & 2 \\
\hline
\end{tabular}




\section{International Journal of Science and Research (IJSR) \\ ISSN (Online): 2319-7064 \\ Index Copernicus Value (2013): 6.14 | Impact Factor (2015): 6.391}

IDA- Iron Deficiency Anemia, Thal- Thalassemia, AAAplastic Anemia, HA- Hemolytic Anemia, MGAMegaloblastic Anemia, AOCD- Anemia of Chronic Disorder.

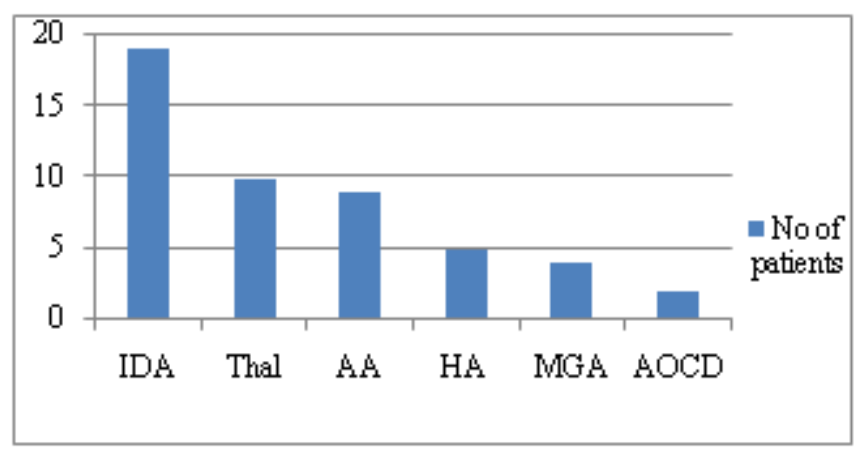

Chart 4: Incidence of various types of anemia

Incidence of Bleeding disorders : This group comprised of patients suffering from platelet disorders and coagulopathies. Of the 10 patients in this group, 7( 70\%) had Idiopathic Thrombocytopenic Purpura(ITP) while 3 patients were diagnosed cases of haemophilia.1079

Table 4: Incidence of various bleeding disorders

\begin{tabular}{|c|c|}
\hline Disease & No of patients \\
\hline ITP & 7 \\
\hline Hemophilia & 3 \\
\hline
\end{tabular}

ITP -Idiopathic Thrombocytopenic Purpura

Incidence of Ocular findings in Blood Dyscrasias : Of the 135 patients examined for ocular changes in blood dyscrasias, 60(44.44\%) showed ocular manifestations of the disease process, highest incidence being the group of patients with hematological malignancies. Of the 76 patients in this group, 41(53.94\%) had some ocular manifestations of the disease process. In the group of patients with different types of anemia, $30.61 \%$ (15 out of 49) showed ocular changes, $40 \%$ (4 out of 10 ) patients suffering from bleeding disorders showed ophthalmic manifestations of the disease.

Table 5: Incidence of ocular changes in various disease groups

\begin{tabular}{|c|c|c|}
\hline Disease group & $\begin{array}{c}\text { No of pts showing } \\
\text { ocular changes }\end{array}$ & Percentage \\
\hline Malignancy & 41 out of 76 & $53.94 \%$ \\
\hline Anemia & 15 out of 49 & $30.61 \%$ \\
\hline Bleeding disorder & 4 out of 10 & $40 \%$ \\
\hline
\end{tabular}

In the group of patients with hematological malignancies, acute leukemia patients showed the highest incidence of ocular changes. In total, 32 patients out of $44(73 \%)$ showed ocular changes with the incidence being $85 \%$ (22 out of 26) in AML and 55\% (10 out of 18) in ALL. In chronic leukemia, 4 out of $10(40 \%)$ showed ocular involvement with CML showing an incidence of $43 \%$ (3 out of 7) and CLL showing an incidence of $33 \%$ (1 out of 3 ). Multiple myeloma patients had ocular changes in 50\% (5 out of 10) cases. None of the patients with lymphomas (11 patients, 8 of NHL and 3 of HD) and MDS ( single case) showed any ocular manifestations.
Table 6: Incidence of ocular changes in hematological malignancies

\begin{tabular}{|l|c|c|}
\hline \multicolumn{1}{|c|}{ Malignancy } & $\begin{array}{c}\text { No of pts showing } \\
\text { ocular changes }\end{array}$ & Percentage \\
\hline Acute leukemia & 32 out of 44 & $73 \%$ \\
AML & 22 out of 26 & $85 \%$ \\
ALL & 10 out of 18 & $55 \%$ \\
\hline Chronic leukemia & 4 out of 10 & $40 \%$ \\
CML & 3 out of 7 & $43 \%$ \\
CLL & 10 out of 18 & $33 \%$ \\
\hline Multiple Myeloma & 5 out of 10 & $50 \%$ \\
\hline MDS & 0 out of 1 & $0 \%$ \\
\hline Lymphomas & 0 out of 10 & $0 \%$ \\
\hline
\end{tabular}

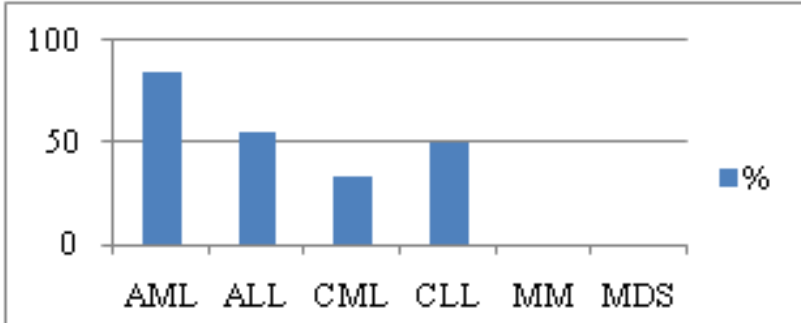

Chart 6: Incidence of ocular changes in hematological malignancies

In the group of patients with anemia, 15 out of 49 patients(30.61\%) showed ocular changes in anemia with 3 patients with Iron deficiency anemia, 5 with Aplastic anemia, 2 with Thalassemia, 4 with hemolytic anemia and 1 patient having Megaloblastic anemia.

Table 7: Incidence of ocular changes in anemia

\begin{tabular}{|c|c|c|}
\hline Disease & No of patients & Percentage \\
\hline IDA & 3 of 19 & $15.7 \%$ \\
\hline AA & 5 of 9 & $55.55 \%$ \\
\hline Thal & 2 of 10 & $20 \%$ \\
\hline HA & 4 of 5 & $80 \%$ \\
\hline MGA & 1 of 4 & $25 \%$ \\
\hline AOCD & 0 of 2 & $0 \%$ \\
\hline Total & 15 of 49 & $30.61 \%$ \\
\hline
\end{tabular}

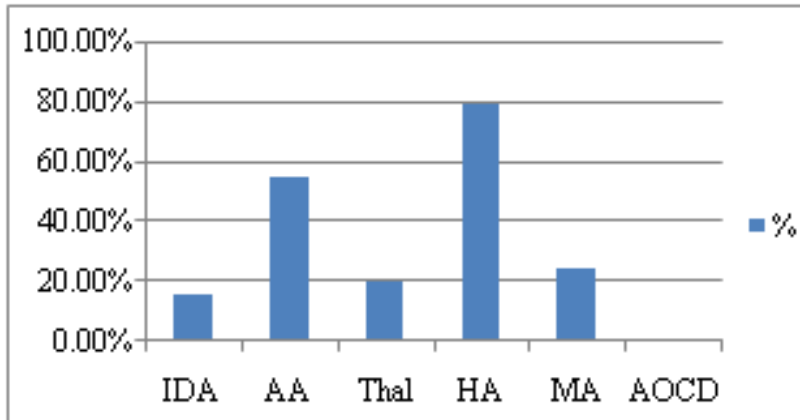

Chart 7: Incidence of ocular changes in anemia

In the group of patients with bleeding disorders, 3 patients with ITP and a single patient with hemophilia showed ocular changes.

Table 8: Incidence of ocular changes in bleeding disorders

\begin{tabular}{|c|c|c|}
\hline Disease & No of patients & Percentage \\
\hline ITP & 3 of 7 & $42.85 \%$ \\
\hline Hemophilia & 1 of 3 & $33.33 \%$ \\
\hline Total & 4 of 10 & $40 \%$ \\
\hline
\end{tabular}




\section{International Journal of Science and Research (IJSR) \\ ISSN (Online): 2319-7064 \\ Index Copernicus Value (2013): 6.14 | Impact Factor (2015): 6.391}

Incidence of changes in various ocular structures: Almost all the ocular structures showed manifestations of the disease. Retina was the commonly involved structure with 47 of 135 patients (34.81\%) showing some changes. Optic nerve, including the optic disc/optic nerve head showed changes in $11.11 \%$ (15 of 135 ) patients. Lens was the only ocular structure in which changes were not seen in any of the patients.

Table 9: Incidence of changes in ocular structures

\begin{tabular}{|c|c|c|}
\hline Ocular structure & $\begin{array}{c}\text { No of pts showing changes, } \\
N=135\end{array}$ & Percentage \\
\hline Orbit & 3 & $2.25 \%$ \\
\hline Lids & 4 & $3 \%$ \\
\hline Conjunctiva & 4 & $3 \%$ \\
\hline Sclera/cornea & 6 & $4.5 \%$ \\
\hline Anterior chamber & 1 & $0.74 \%$ \\
\hline Lens & Nil & $0 \%$ \\
\hline Vitreous & 1 & $0.74 \%$ \\
\hline Uvea & 2 & $1.5 \%$ \\
\hline Retina & $\mathbf{4 7}$ & $\mathbf{3 4 . 8 1 \%}$ \\
\hline Optic nerve/Disc & 15 & $11.11 \%$ \\
\hline
\end{tabular}

Retina, in addition to being the most common ocular structure involved showed most varied types of manifestations in different patients as retinal hemorrhages( most common) predominantly dot -blot, flame shaped, white centered and subhyaloid (preretinal) hemorrhages ;dilated and tortuous retinal vessels, vascular sheathing, exudates(hard and soft cotton wool spots);macular edema; pigment epithelial detachment and central retinal vein occlusion, all patients labeled to be having 'retinopathy of blood dyscrasias'. Of the 47 patients showing retinopathy, only 6 were of pediatric age group $(<18$ yrs) while 41 belonged to adult age group. The youngest was a 3 year old male child suffering from ALL. Then again out of 26 acute leukemia patients, Acute Myeloid Leukemia with 18 patients showed the maximum number of different retinal changes followed by 8 patients of Acute Lymphoblastic Leukemia ;5 patients each of Multiple Myeloma and Aplastic Anemia; 3 patients of Chronic Myeloid leukemia and Iron Deficiency Anemia; 1 patient each of Chronic Lymphocytic Leukemia, Thalassemia, Idiopathic Thrombocytopenic Purpura, Hemolytic anemia and Megaloblastic anemia.

Table 10: Significant other ocular changes in our study

\begin{tabular}{|c|c|c|c|c|c|c|c|c|}
\hline Diagnosis & Orbit & Lids & Conj & $\begin{array}{c}\text { Cornea/ } \\
\text { Sclera }\end{array}$ & $\mathrm{AC}$ & Uvea & Vitreous & ON/OD \\
\hline AML & Proptosis-2 & Ecchy-1 & SCH-2 & $\begin{array}{c}\text { Mass at limbus-1 } \\
\text { Icterus-1 }\end{array}$ & Infltr by mass-1 & Leukem infltr-2 & VH-1 & $\begin{array}{c}\text { Papilloed-2 } \\
\text { Pallor-2 } \\
\end{array}$ \\
\hline ALL & Proptosis-1 & Swelling-1 & SCH-1 & - & - & - & - & $\begin{array}{c}\text { Papilloed-2 } \\
\text { Pallor-1 } \\
\text { Infiltration-1 }\end{array}$ \\
\hline AA & - & - & SCH-1 & - & - & - & - & Pallor -2 \\
\hline Thal & - & - & - & - & - & - & - & Pallor -1 \\
\hline HA & - & - & - & Icterus-4 & - & - & - & Pallor -1 \\
\hline $\mathrm{HM}$ & - & Ecchy-1 & - & - & - & - & - & - \\
\hline
\end{tabular}

SCH- Sub conjunctival hemorrhage, AC- Anterior Chamber, ON- Optic Nerve, OD- Optic Disc, VH- Vitreous Humour, Infltr- Infiltration, Conj- Conjunctiva, Ecchy- Ecchymosis, Papilloed- Papilloedema

\section{Discussion}

Many studies and case reports highlighting the ocular manifestations of different blood dyscrasias are present in the literature. However, the results shown by them are not uniform and the significance of these changes and their relationship with hematological parameters have been reported differently by various studies. However, when reviewing the results of different studies, the methodology of the study has to be taken in to account, as both clinical and pathological studies are present.

In the present study, 135 patients with different blood dyscrasias were examined at R. I.O, Gauhati Medical College Hospital with 49 females and 86 males. The study population ranged from 7 months to 81years and 35 patients below 18 years and 100 patients in the adult group.

Patients with different blood disorders ranging from different types of anemia to leukemia, multiple myeloma, lymphoma and bleeding disorders were examined .Complete ophthalmic examination and note of blood counts were made.
In our study, 15 out of 49 suffering from different types of anemia showed ocular changes. Retinopathy was seen in 11 out $49(22.5 \%)$ patients with anemia and all showed retinal hemorrhages.

Table: Comparision of retinopathy in patients with anemia in different studies

\begin{tabular}{|c|c|}
\hline Study & Incidence of Retinopathy \\
\hline $\begin{array}{c}\text { Rubenstein and Co- } \\
\text { workers }{ }^{5}(1968)\end{array}$ & $\begin{array}{c}19 \text { of } 67 \text { patients examined } \\
(28.35 \%)\end{array}$ \\
\hline Merin and Freund ${ }^{6}$ (1968) & $\begin{array}{c}20 \text { of } 89 \text { patients examined } \\
(22.5 \%)\end{array}$ \\
\hline $\begin{array}{l}\text { Holt and Gordon }- \text { Smith }^{7} \\
\text { (1969) }\end{array}$ & $\begin{array}{c}16 \text { of } 66 \text { patients examined } \\
(24.25 \%)\end{array}$ \\
\hline Kataria et all ${ }^{8}(1983)$ & $\begin{array}{c}6 \text { of } 40 \text { patients examined } \\
(15 \%)\end{array}$ \\
\hline Our study (2008) & $\begin{array}{c}11 \text { of } 49 \text { patients examined } \\
(22.5 \%)\end{array}$ \\
\hline
\end{tabular}

Thus the incidence of retinopathy in anemia in the present study was similar to the earlier studies and the findings were similar too. 


\section{International Journal of Science and Research (IJSR) \\ ISSN (Online): 2319-7064 \\ Index Copernicus Value (2013): 6.14 | Impact Factor (2015): 6.391}

In our study, 10 out of 135 patients had bleeding disorders, out of which 7 were suffering from Idiopathic thrombocytopenic purpura and 3 had hemophilia . 3 patients out of 7 (43\%) and 1 out of 3(33\%) showed ocular changes.

Holt and Gordon- Smith ${ }^{7}$ in their study did not find any retinal hemorrhage in cases that had thrombocytopenia as the sole abnormality in peripheral blood. However, Kataria et al ${ }^{8}$ in their study of fundus, examined two cases of thrombocytopenic purpura and found retinal hemorrhage in one of them. Rubenstein, Daniel and Harold ${ }^{14}$ in their study of 123 patients with hemophilia reported ocular findings ( orbital or periorbital hemorrhage being most common) in 25 patients.

As the number of cases with bleeding disorders is less and majority of literature is in the form of isolated case reports, it is difficult to comment.

In our study, a total of 76 patients were diagnosed with hematological malignancies ,out of which 26 patients with AML, 18 with ALL, 7 with CML, 3 with CLL, 10 with multiple myeloma, 1 with MDS and 11 patients had lymphoma(8- NHL, 3-HD).The overall ocular changes in them was $53.5 \%(41$ of 76$)$.

Table: Comparison of incidence of ocular involvement( mostly metastasis and infiltrations) in patients with hematological malignancies in different studies

\begin{tabular}{|c|c|}
\hline Investigator & Incidence \\
\hline Allen and Straatsma ${ }^{9}$ (1961) & 38 of $76(50 \%)$ \\
\hline Robb,Ervin et al ${ }^{10}$ (1979) & $30-44$ of $60(50-73 \%)$ \\
\hline Kincaid and Green ${ }^{1}$ (1983) & 284 of $357(50 \%)$ \\
\hline Nelson et al ${ }^{11}(1983)$ & 33 of $117(28 \%)$ \\
\hline Schachat et al ${ }^{12}$ (1989) & 51 of $120(42 \%)$ \\
\hline Leonardy et al ${ }^{13}$ (1990) & 42 of $135(31 \%)$ \\
\hline Our study (2008) & 41 of $76(53.5 \%)$ \\
\hline
\end{tabular}

The wide variation in incidence of ocular involvement in these studies may be ascribed to majority of them being pathological studies whereas ours was a clinical study.

Table: Comparison of incidence of retinopathy in hematological malignancies in different studies

\begin{tabular}{|l|l|}
\hline \multicolumn{1}{|c|}{ Investigator } & \multicolumn{1}{|c|}{$\begin{array}{c}\text { Retinal involvement/ } \\
\text { retinal hemorrhage }\end{array}$} \\
\hline Straatsma et al ${ }^{9}(1961)$ & Most frequent \\
\hline${\text { Holt and Gordon-Smith }{ }^{7}(1969)}$ 21 of $48(44 \%)$ \\
\hline${\text { Kincaid and Green }{ }^{1}(1983)}_{106 \text { of } 357(30 \%)}$ \\
\hline${\text { Kataria et al }{ }^{8}(1983)}^{12}$ & 28 of $50(56 \%)$ \\
\hline Schachat et al ${ }^{12}(1989)$ & 29 of $120(24 \%)$ \\
\hline Our study $(2008)$ & 35 of $76(46 \%)$ \\
\hline
\end{tabular}

The wide variation may be due to some studies being pathological and some clinical and the dependence upon disease state. Vitreous hemorrhage was seen in only a single patient in the present study who was a female patient with acute myeloid leukemia. Schachat and co-workers 12 reported vitreous hemorrhage in 3 patients and all the three patients in their series had myeloid leukemia.

The optic nerve and optic disc involvement was seen in 9 patirents as papilloedema , infiltration of the nerve( along with proptosis bilaterally), and pallor of the optic disc. Of the 5 patients with papilloedema, 2 had AML , 1 had ALL and 1 had CML. Holt and Gordon-Smith ${ }^{7}$ found papilloedema in one case out of 33 case of acute leukemia. Kincaid and Green ${ }^{1}$ have reported some type of optic nerve involvement to be slightly more common in acute leukemia (43 out of 233 eyes) than chronic leukemia (15 out of 97 eyes).

Overall 47 patients showed retinopathy. The difference in mean total leukocytic count(TLC) of the patients with acute leukemia showing retinopathy to those without retinopathy was not found statistically significant but for anemia patients, the mean TLC in patients with retinopathy was significantly lower than those without retinopathy ( $\mathrm{p}=$ 0.0019). However it is difficult to explain the role of low count in causing retinopathy .When platelet count and hemoglobin concentration were analyzed, they were lower in those with retinopathy in leukemia, implying that difference in their mean being statistically significant $(p=0.009$ for platelets their and $\mathrm{p}=0.005$ for hemoglobin). This may imply that patients having acute leukemia with lower platelet count and lower hemoglobin concentration have greater chances of developing retinopathy. The statistical analysis also revealed that the means of platelet count and hemoglobin concentration were significantly lower in the patients with anemia and retinopathy than those without retinopathy $(p<0.001$ for platelet count, $p=0.003$ for hemoglobin\}. Other parameters showed no significant difference due to small sample size.

\section{Conclusion}

Males were seen to be more affected than females. All the ocular structures except the lens showed changes in blood dyscrasias. Retina was the most common affected structure seen mainly in acute leukemia and retinal hemorrhage was the most common finding. As these results were not consistent between different disease groups, we may assume that lower platelet count and hemoglobin concentration are more predisposed to having retinopathy. Published literature is also not consistent on this subject. However, there was definite improvement of ocular changes with improvement in the blood picture with treatment. The present study was found to be satisfactory and within clinically acceptable limits of the different reported study groups.

\section{References}

[1] Kincaid MC, Green WR. Ocular and orbital involvement in leukemia. Surv Ophthalmology 1983;27:211

[2] Guyer DR, Schachat AP,Vitale S et al.Leukemic retinopathy: Relationship between fundus lesions and hematologic parameters at diagnosis. Ophthalmology 1989;96:860

[3] Kumar, Abbas and Fausto: Robbins and Cotran Pathologic Basis of disease $8^{\text {th }}$ edition

[4] Wintrobe's Clinical Hematology, $10^{\text {th }}$ edition

[5] Rubenstein RA, Yanoff M, Albert DM. Thrombocytopenia, Anemia and retinal hemorrhage. Am J Ophthalmol 1968;65:435 


\section{International Journal of Science and Research (IJSR) \\ ISSN (Online): 2319-7064}

Index Copernicus Value (2013): 6.14 | Impact Factor (2015): 6.391

[6] Merin S, Freund M: Retinopathy in severe anemia. Am J Ophthalmol 66: 1102,1968

[7] Holt JM, Gordon-Smith EL. Retinal abnormalities in diseases of the blood Br J Ophthalmol 1969: 53:145

[8] Kataria VC, Audich KL, Narang SK, Khamar BM. The fundus findings in blood dyscrasias. Indian $\mathrm{J}$ Ophthalmol 1983;31:899-902

[9] Allen RA, Straatsma BR. Ocular involvement in leukemia and allied disorders Arch Ophthalmol 1961; 66:490

[10] Robb RM, Erwin LD, and Sallen SE. An autopsy study of eye involvement in acute leukemian childhood. Med. Pediatr. Oncol.6:171,1979

[11]Nelson CC, Hertzberg BS and Klinworth GK. A histopathologic study of 716 unselected eyes in patients with cancer at the time of death . Am J. Ophthalmol. 95:788, 1983

[12] Schachat AP,Markowitz JA, GuyerDR et al.Ophthalmic manifestations of Leukemia, Arch Ophthalmol 1989;107:697

[13] Leonardy NJ, Rupani M, Dent G et al. Analysis of 135 autopsy eyes for ocular involvement in leukemia.Am J Ophthalmol 1990;109:436

[14] Rubenstein RA, Albert DM, Scheie HG: Ocular complications of hemophilia .Arch Ophthalmol $76: 230,1966$ 